\title{
Axial service limit state analysis of drilled shafts using probabilistic approach
}

\author{
ANIL MISRA $^{1, \star}$ and LANCE A. ROBERTS ${ }^{2}$ \\ ${ }^{1}$ Professor of Civil Engineering, University of Missouri-Kansas City, 5100 Rockhill Road, $350 \mathrm{H}$ \\ Flarsheim Hall, Kansas City, MO, 64110, USA \\ ${ }^{2}$ Bridge Engineer, TranSystems Corporation, 2400 Pershing Road, Suite 400, Kansas City, MO, \\ 64108, USA
}

(Received 23 February 2005; revised 3 October 2005)

\begin{abstract}
Drilled shafts are, typically, designed by considering the axial ultimate limit state. In this design methodology, the axial displacement requirements are verified once the design is completed. As an alternative, drilled shafts may be designed by considering the axial service limit state. Service limit state foundation design is more efficient when done using the load and resistance factor design (LRFD) approach. Furthermore, reliability may be rationally incorporated into the design process that utilizes the LRFD method. In this paper, we develop probabilistic approaches for axial service limit state analysis of drilled shafts. The variability of shaft-soil interface properties is modeled by lognormal probability distribution functions. The probability distributions are combined with a closed-form analytical relationship of axial loaddisplacement curves for drilled shafts. The closed-form analytical relationship is derived based upon the " $\mathrm{t}-\mathrm{z}$ " approach. This analytical relationship is used with the Monte Carlo simulation method to obtain probabilistic load-displacement curves, which are analyzed to develop methods for determining the probability of drilled shaft failure at the service limit state. The developed method may be utilized to obtain resistance factors that can be applied to LRFD based service limit state design.
\end{abstract}

Key words. drilled shaft, failure probability, load-displacement relation, serviceability.

Notation: $D$ : drilled shaft diameter, $\mathrm{mm} ; \mathrm{d} P / \mathrm{d} u$ : drilled shaft initial stiffness, $\mathrm{kN} / \mathrm{m}$; $E_{\mathrm{s}}$ : soil elastic modulus, $\mathrm{kN} / \mathrm{m}^{2} ; K$ : shear modulus of shaft-soil interface, $\mathrm{kN} / \mathrm{m}^{2} ; K_{\mathrm{c}}$ : axial stiffness of debond zone, $\mathrm{MN} ; K_{\mathrm{m}}$ : drilled shaft axial stiffness, MN; $K_{\mathrm{t}}$ : drilled shaft tip soil stiffness, $\mathrm{kN} / \mathrm{m} ; L_{\mathrm{b}}$ : shaft interaction zone length, $\mathrm{m} ; L_{\mathrm{d}}$ : shaft noninteraction length, $\mathrm{m} ; P$ : drilled shaft load, $\mathrm{kN} ; P_{\mathrm{t}}:$ drilled shaft tip resistance force, $\mathrm{kN} ; P_{\mathrm{u}}$ : drilled shaft ultimate pullout capacity, $\mathrm{kN} ; q$ : shear force per unit length, $\mathrm{kN} / \mathrm{m} ; q_{\mathrm{o}}$ : yield strength of shaft-soil interface, $\mathrm{kN} / \mathrm{m} ; u$ : displacement, $\mathrm{mm} ; u_{\mathrm{o}}$ : interface displacement at yield, $\mathrm{mm} ; u_{\mathrm{t}}$ : tip displacement, $\mathrm{mm} ; \bar{u}$ : deformation at top of drilled shaft, mm; $U$ : non-dimensional displacement; $\bar{u}$ : non-dimensional displacement at top of interaction zone; $x$ : location along the drilled shaft length; $\alpha$ : normalizing factor, $\mathrm{cm} ; \kappa$ : non-dimensional factor; $\lambda$ : scaling factor; $\mu_{\mathrm{s}}$ : tip soil Poisson's ratio; $\tau_{\mathrm{u}}$ : ultimate shear strength of shaft-soil interface, $\mathrm{kN} / \mathrm{m}^{2}$; $\xi$ : nondimensional length; $\xi_{\mathrm{o}}$ : location of transition point.

^ Corresponding author: Anil Misra, Professor of Civil EngineeringUniversity of Missouri-Kansas City, 5100 Rockhill Road, 350H Flarsheim Hall, Kansas City, MO, 64110, USA (e-mail: misraa@umkc.edu; phone 816-235-1285; fax 816-235-1260) 


\section{Introduction}

Drilled shafts are, traditionally, designed by considering the axial ultimate limit state following the so-called working stress design (WSD) or the allowable stress design (ASD) methodology. In this design methodology, the axial displacement requirements are verified once the design is completed. As an alternative, drilled shafts may be designed by considering the axial service limit state. In this alternative design methodology, reliability based approaches, such as the load and resistance factor design (LRFD) approach, may be rationally incorporated. As discussed in FHWA (1999) and Paikowsky et al. (2004), the LRFD approach of drilled shaft design has the following advantages: (1) foundation design is easier and efficient when the structure is designed using LRFD method, as the load combinations need not be redefined, and (2) reliability may be rationally incorporated into the design process. In the LRFD method, the design may be evaluated for a variety of load combinations, including those for normal strength requirements and those for extreme-event-loading requirements. Furthermore, drilled shaft axial capacity may be evaluated at both the ultimate limit state and the service limit state AASHTO (2004).

This paper presents probabilistic approaches for axial service limit state analysis of drilled shafts based upon a probabilistic mathematical model for drilled shaft load-displacement behavior. The soil-drilled shaft interaction is considered explicitly in the model development along the lines of the " $t-z$ " approach. To ensure model simplicity, we consider the shaft-soil interface to be homogeneous with depth and ideally elasto-plastic. Consequently, we obtain closed form analytical relationships for drilled shaft load-displacement behavior. These expressions are given in terms of the shaft-soil interface properties: the shear modulus of shaft-soil interface sub-grade reaction, $K$, the ultimate shaft-soil interface shear strength, $\tau_{\mathrm{u}}$, and the modulus of tip soil sub-grade reaction, $K_{\mathrm{t}}$. In traditional analysis, "characteristic" values of shaft-soil parameters are used to obtain the deterministic loaddisplacement curves. However, considering the uncertainties associated with drilled shaft installation, a probabilistic analysis is desirable. In recent years, the application of probabilistic analysis and reliability based design in geotechnical engineering is being increasingly recognized (see Baecher and Christian, 2003; Christian, 2004).

Uncertainties in the shaft-soil interface properties may arise from three primary sources: inherent variability, measurement error, and transformation uncertainties (Phoon and Kulhawy, 1999). Inherent variability results from the natural processes of soil deposition, consolidation etc., while the measurement error and transformation uncertainties result from soil testing and the attempts to correlate soil tests into design soil properties. The purpose of this paper is to establish the probabilistic behavior of the shaft head displacement due to these uncertainties. To that end, we utilize probability distribution functions for shaft-soil interface properties along with the derived analytical relationships to obtain probabilistic load-displacement curves for drilled shafts. 
Since the derived closed form solutions for drilled shaft head displacement are complex, typical analytical probabilistic methods, such as the first-order secondmoment method, cannot be used to determine the probability distribution of shaft head displacement. Instead, the Monte Carlo simulation method is used. The shear modulus of the shaft-soil subgrade reaction, $K$, and the ultimate shaft-soil shear strength, $\tau_{\mathrm{u}}$, are assumed to be random variables and are characterized statistically by the lognormal probability distribution functions defined by a mean and standard deviation. Probability curves are generated in order to quantify the probability of service limit state failure given an allowable head displacement.

\section{Drilled Shaft-Soil Interaction and Variability of Shaft-Soil Interface Properties}

The drilled shaft-soil interaction and the load transfer mechanism is schematically shown in Figure 1. It is assumed that the load-transfer to the ground occurs through the soil-concrete interface of the drilled shaft as represented by spring-slider system in Figure 1. Similar assumptions are commonly made for analytical and numerical models for load-displacement behavior (or the so called " $t-z$ " curves) of piles and drilled shafts (cf. Scott, 1981; Kraft et al., 1981; Reese and O’Neill, 1987; FHWA, 1999; Misra and Chen, 2004). Thus, the drilled shaft-soil interface is assumed to behave as an ideal elastic-plastic material, both in the drained and the undrained conditions.

Figure 2 shows the idealized force-displacement behavior of the spring-slider system as depicted by the shear force per unit length $q$, versus displacement $u$, curve. Here $K$ is the shear modulus of shaft-soil interface sub-grade reaction, $q_{\mathrm{o}}$ is the yield strength of the shaft-soil interface given by the product of shaft perimeter $\pi D$ and the

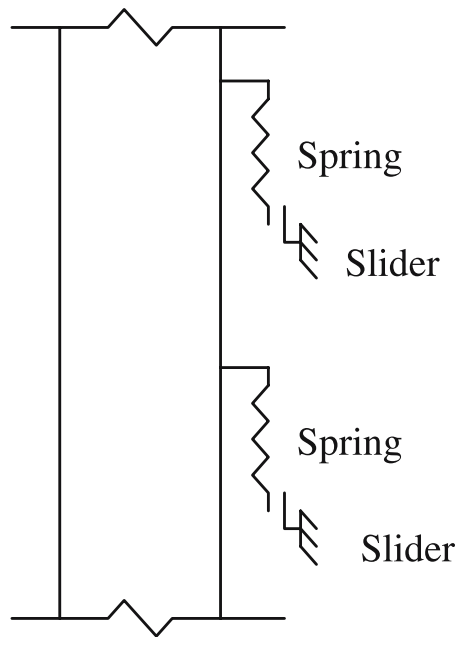

Figure 1. Spring and slider model for drilled shaft-soil interface. 


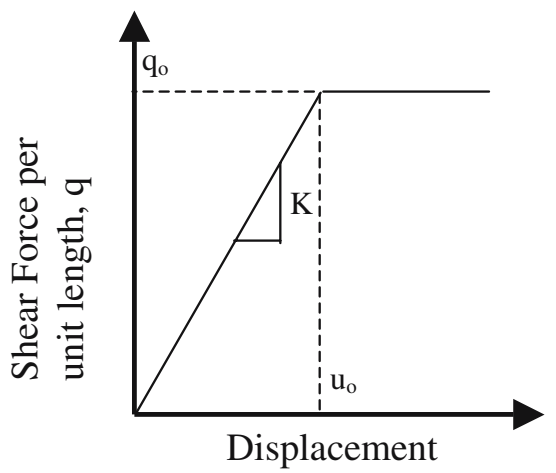

Figure 2. Drilled shaft-soil interface behavior.

ultimate shear strength of shaft-soil interface in drained or undrained conditions denoted by $\tau_{\mathrm{u}}$, and $u_{\mathrm{o}}=q_{\mathrm{o}} / K$ is the interface displacement at yield. The interface properties are related to the soil parameters and the construction techniques. Moreover, the interface properties may follow the stratification of the natural soil; however, for simplicity of analysis that could benefit engineers in drilled shaft design, a homogeneous interface is assumed. The advantage of this assumption is that the constant values of $K$ and $\tau_{\mathrm{u}}$ may be used as representative shaft-soil interface parameters for a given installation.

In a deterministic analysis, a characteristic value of the shaft-soil interface properties, $K$ and $\tau_{\mathrm{u}}$, are used to obtain a representative shaft load-displacement curve. The load-displacement curve is then used as a basis for design and/or analysis of the drilled shaft foundation. However, these shaft-soil interface properties may vary from one installation to the other at a given site due to the natural variations in soil deposits and construction procedures. Therefore, it is desirable to describe the interface properties statistically using probability distribution functions based upon their means and standard deviations. From a review of the literature, there does not appear to be any single probability distribution function that has been used to describe shaftsoil interface variability. Since the shaft-soil interface properties are non-negative, the use of non-Gaussian probability distribution function, such as lognormal, gamma, chi-square and beta is necessary (see for example Chalermyanont and Benson, 2004; Griffiths and Fenton, 2004). In this paper, the shaft-soil interface properties, $\tau_{\mathrm{u}}$ and $K$, are assumed to be random variables and are described statistically by the lognormal probability distribution function.

Several probabilistic approaches exist for evaluation of functions that involve random variables. Since the load-displacement relationships are non-linear functions of these interface properties, closed-form probabilistic relations are not possible. Moreover, due to the complexity of the head displacement functions, truncated Taylor series expansion methods, such as the first-order, second moment method (FOSM), are cumbersome to use. However, because the probability distribution functions of the soil properties have been initially defined by the lognormal distribution, the so called 
exact probabilistic solution methods (Harr, 1996), may be utilized to solve for the shaft head displacement. Therefore, the Monte Carlo simulation method is utilized here to obtain probabilistic load-displacement relations for drilled shafts.

In a Monte Carlo simulation, a large set of randomly generated numbers having a defined probability distribution function is generated. During each trial, a random number is generated from within the probability distribution function for each random variable. Figure $3 a$ and $b$ show the results of random values of shaft-soil interface properties, $K$ and $\tau_{\mathrm{u}}$, generated using a lognormal distribution function. In Figure 3a, the solid lines depict the shape of the lognormal distribution function for a mean value equal to $89 \mathrm{MPa}$ and standard deviation of $27 \mathrm{MPa}$. The symbols superimposed over the lognormal distribution function depict the histogram of 5000 values that were randomly generated by a Mathcad program for the shear modulus, $K$, based upon the lognormal distribution function with the same parameters. Similarly, in Figure $3 b$, the
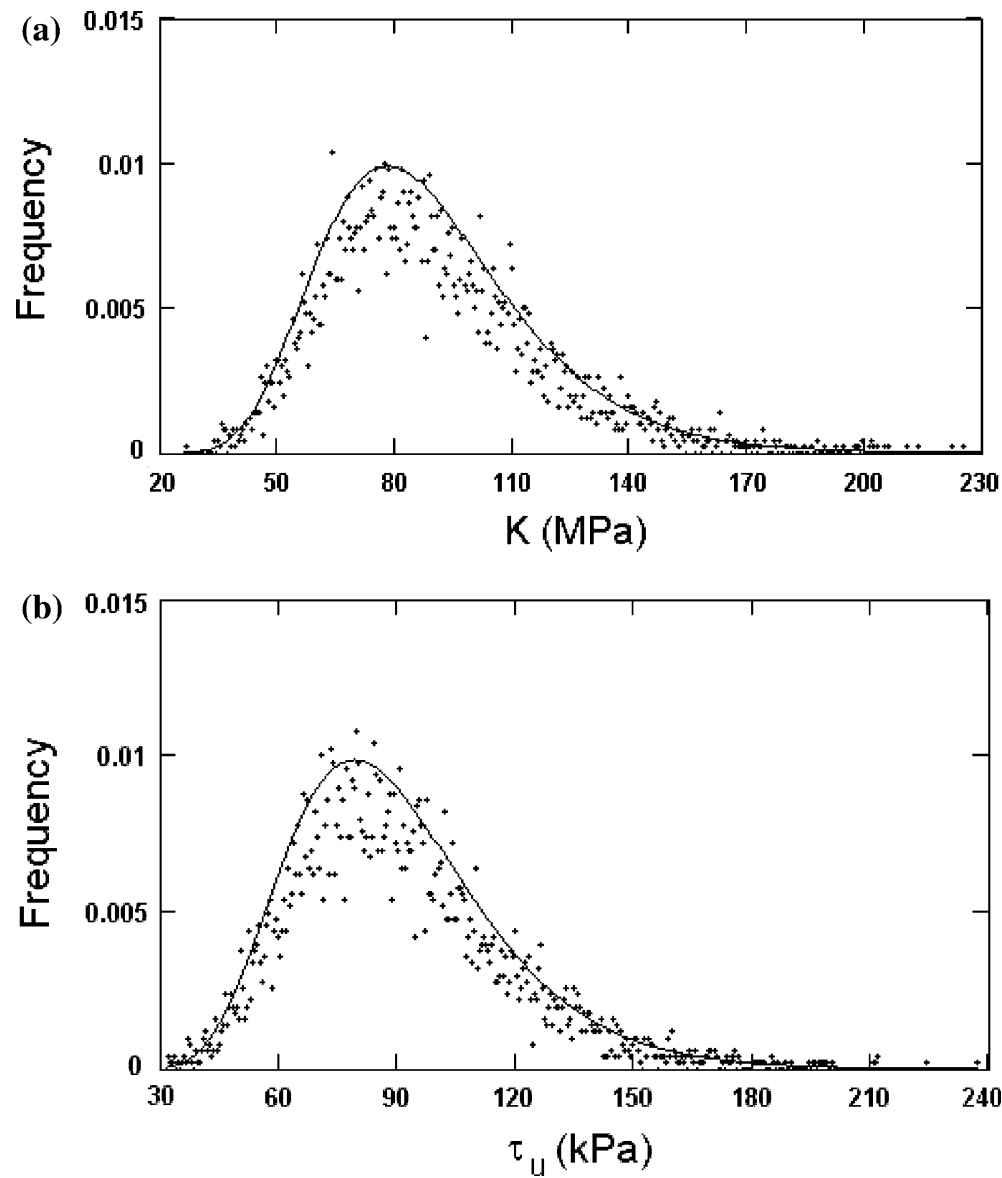

Figure 3. (a) Probability distribution histogram for random generation of $K$ based upon a mean value of $89 \mathrm{MPa}$ with a standard deviation equal to $27 \mathrm{MPa}$. (b) Probability distribution histogram for random generation of $\tau_{\mathrm{u}}$ based upon a mean value of $90 \mathrm{kPa}$ with a standard deviation equal to $27 \mathrm{kPa}$. 
solid lines depict the shape of the lognormal distribution function for a mean value equal to $90 \mathrm{kPa}$, and standard deviation of $27 \mathrm{kPa}$ and the symbols depict the histogram of 5000 values that were randomly generated for the ultimate shear strength, $\tau_{\mathrm{u}}$, based upon the lognormal distribution function with the same parameters.

The required number of Monte Carlo trials is based upon achieving a particular level of reliability (Harr, 1996; Baecher and Christian, 2003). Each trial in a Monte Carlo simulation is assumed to be an independent experiment with a certain probability of success, $P$. Based upon this assumption, the trials will generate a binomial distribution. When the number of trials, $N$, is large, the binomial distribution can be approximated as a Gaussian (normal) distribution with a mean of NP and a standard deviation of $(N P(1-P))^{1 / 2}$ (Harr, 1996). The level of reliability, or confidence interval, can be set by selecting the level of uncertainty. Based upon this reliability principle, the number of Monte Carlo trials required for a confidence level of $90 \%$ is approximately 4500 (Harr, 1996). For the results reported in this paper, a Monte Carlo simulation with 5000 trials was conducted.

\section{Elastic Shaft-Soil Interaction Model}

Given the manner in which drilled shafts are installed, the load transfer occurs via the shaft-soil interface in the interaction zone, $L_{\mathrm{b}}$. The remainder of the shaft-soil interface is considered to be non-interacting having negligible shear resistance. The non-interacting zone is considered to be the top $0.3-1.5 \mathrm{~m}$ depending upon the ground disturbance, fill placement and construction sequence used. As the drilled shaft is subjected to loading, the shaft-soil interface in the interaction zone, $L_{\mathrm{b}}$, first deforms elastically. Subsequently, the interface begins to yield as the load is increased further. The interface yield initiates at the top of the interaction zone and progresses to the bottom of the shaft. The shaft itself is assumed to behave elastically throughout considering that the load required to reach the interface yield strength is much smaller than that required to yield the concrete.

Following the procedure presented by Scott (1981) in the context of pile analysis, under elastic deformation of the shaft-soil interface, the force balance of the shaftsoil interaction of a slice $\Delta z$ is given by the following equilibrium equation:

$$
q(z)-K u(z)=0
$$

where, $q(z)$ is the shear force per unit length along the shaft, $K$ is the shear modulus of shaft-soil interface sub-grade reaction, and $u(z)$ is the shaft deformation at that location. Denoting the shaft axial stiffness to be $K_{\mathrm{m}}$, the axial force in the shaft is given by $K_{\mathrm{m}} \mathrm{d} u / \mathrm{d} z$ and hence, the shear force per unit length $q(z)$ is obtained to be:

$$
q(z)=K_{\mathrm{m}} \frac{\mathrm{d}^{2} u}{\mathrm{~d} z^{2}}
$$

Using a non-dimensionalized length $\xi=z / L_{\mathrm{b}}$, the governing equation Equation (1) may be written as: 


$$
\frac{\mathrm{d}^{2} u}{\mathrm{~d} \xi^{2}}-\lambda^{2} u(\xi)=0 \quad \text { for } 0 \leq \xi \leq 1
$$

where scaling factor $\lambda$ is given by:

$$
\lambda^{2}=\frac{K L_{\mathrm{b}}^{2}}{K_{\mathrm{m}}}
$$

Considering the shaft interaction zone, $L_{\mathrm{b}}$, may range from 3 to $30 \mathrm{~m}$, and the ratio of interface sub-grade reaction and shaft axial stiffness, $K / K_{\mathrm{m}}$, may vary from $10^{-3} \mathrm{~m}^{-2}$ to $0.1 \mathrm{~m}^{-2}$, average values of scaling factor, $\lambda$, would range from as low as 0.1 for a softer interface to as high as 10 for a stiff interface. However, its probability distribution will depend upon that of shaft-soil interface sub-grade reaction, $K$, and as evident from Equation (4), is directly proportional to the square root of $K$. Figure 4a gives a plot of the probability distribution histogram
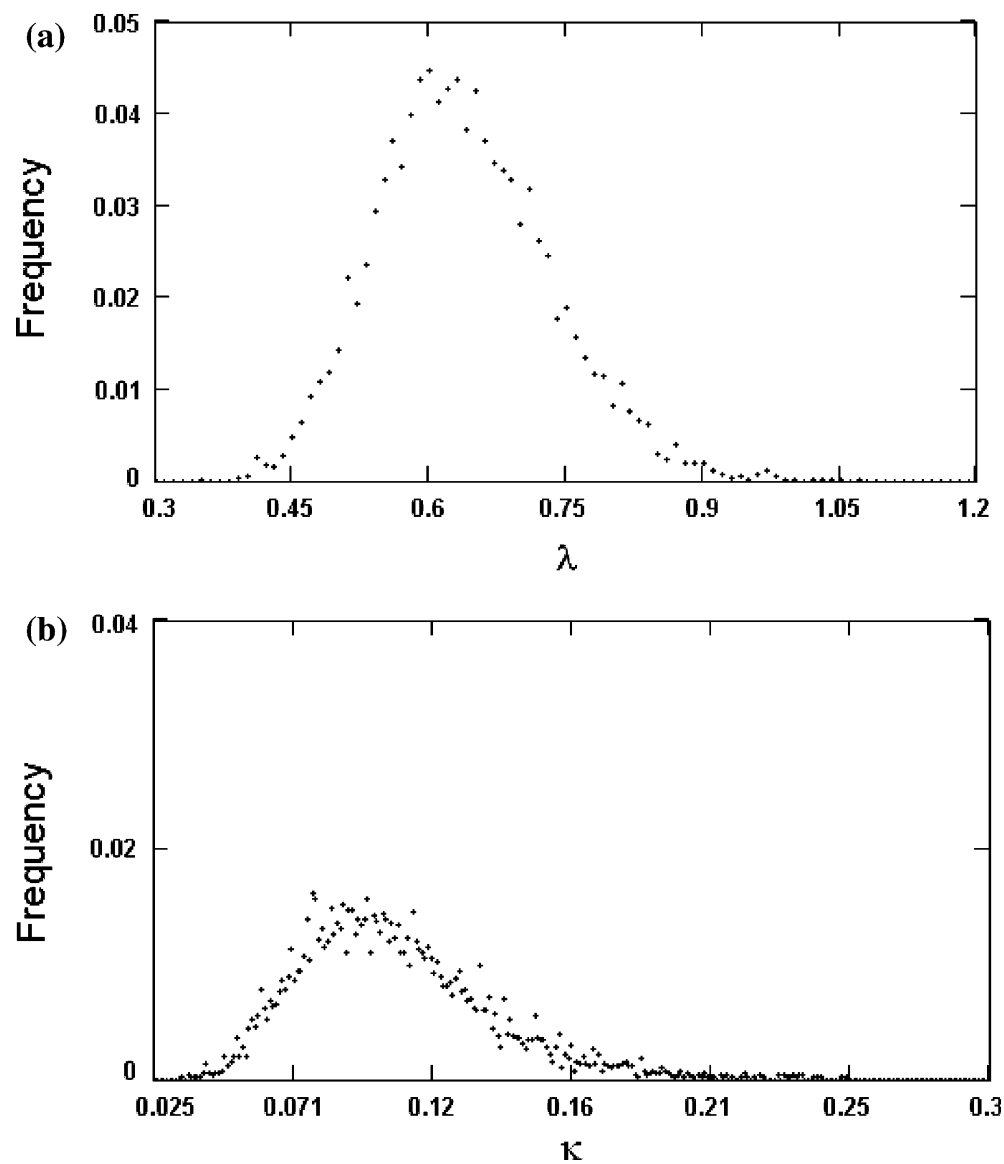

Figure 4. (a) Probability distribution histogram for $\lambda$. (b) Probability distribution histogram for $\kappa$. 
for the scaling factor, $\lambda$, calculated using Equation (4) and the probability distribution of the shear modulus of the shaft-soil interface sub-grade reaction, $K$, given in Figure 3a. In these computations, the shaft diameter $=900 \mathrm{~mm}$, shaft length $=10 \mathrm{~m}$, the interaction zone, $L_{\mathrm{b}}=9 \mathrm{~m}$, and modulus of elasticity of the drilled shaft $=26300 \mathrm{MPa}$. The expected value of $\lambda$ is found to be approximately 0.72 .

Under compression, the drilled shaft will develop a tip resistance force, $P_{\mathrm{t}}$ proportional to the tip displacement, $u_{\mathrm{t}}$ given by:

$$
P_{\mathrm{t}}=K_{\mathrm{t}} u_{\mathrm{t}}
$$

where $K_{\mathrm{t}}$ is the tip soil stiffness. Based upon theories for rigid punch bearing upon elastic half-space, the tip soil stiffness, $K_{\mathrm{t}}$, may be related to shaft diameter and elastic properties of tip soil as follows (Johnson, 1985):

$$
K_{\mathrm{t}}=\frac{0.3 \pi D E_{\mathrm{s}}}{\left(1-\mu_{\mathrm{s}}^{2}\right)}
$$

where $E_{\mathrm{s}}$ is the tip soil elastic modulus and $\mu_{\mathrm{s}}$ is tip soil Poisson's ratio.

Considering that the shaft has an applied load, $P$, at the top and a tip force given by Equation (5), Equation (3) may be solved to obtain the following expression for normalized shaft deformation:

$$
U(\xi)=\frac{1}{\alpha} u(\xi)=\frac{P}{P_{\mathrm{u}}} \frac{\cosh \lambda \xi+\kappa \lambda \sinh \lambda \xi}{\lambda(\sinh \lambda+\kappa \lambda \cosh \lambda)} \quad \text { for } 0 \leq \xi \leq 1
$$

where $P_{\mathrm{u}}=\pi D L_{\mathrm{b}} \tau_{\mathrm{u}}$ and the non-dimensional factors $\alpha$ and $\kappa$, are given as:

$$
\alpha=\frac{P_{\mathrm{u}} L_{\mathrm{b}}}{K_{\mathrm{m}}} \text { and } \kappa=\frac{K_{\mathrm{t}}}{K L_{\mathrm{b}}}
$$

Thus, the elastic deformation, $\bar{u}$, at the shaft head under an applied load, $P$, is obtained as:

$$
\bar{u}=\frac{P L_{\mathrm{b}}}{K_{\mathrm{m}}} \frac{\cosh \lambda+\kappa \lambda \sinh \lambda}{\lambda(\sinh \lambda+\kappa \lambda \cosh \lambda)}+\frac{P L_{\mathrm{d}}}{K_{\mathrm{m}}}
$$

The factors that control the non-dimensional factor, $\kappa$, are the ratio of shaft diameter and interaction length, $D / L_{\mathrm{b}}$, and the ratio of tip soil modulus of elasticity and the shaft-soil interface sub-grade reaction, $E_{\mathrm{s}} / K$. Considering that $D / L_{\mathrm{b}}$ ranges from $10^{-2}$ to $3 \times 10^{-2}$ and $E_{\mathrm{s}} / K$ ranges from $2 \times 10^{-2}$ to 8 , the average value of non-dimensional factor, $\kappa$, would typically range from $10^{-4}$ to $10^{-1}$. However, its probability distribution will depend upon that of shaft-soil interface sub-grade reaction, $K$ and as evident from Equation (9), is inversely proportional to $K$. Figure $4 \mathrm{~b}$ gives a plot of the probability distribution histogram for the non-dimensional factor, $\kappa$, calculated using Equation (9) and the probability distribution of $K$ given in Figure 3a. In these computations, the elastic soil modulus $=75 \mathrm{MPa}$, and soil Poisson's ratio $=0.4$. The expected value of $\kappa$ is found to be approximately 0.086 . 


\section{Elasto-Plastic Shaft-Soil Interaction Model}

As the load on the drilled shaft is increased, the shaft-soil interface will begin to yield from the top of the interaction zone. Now, considering the force balance of slices $\Delta z$ at location $z$ in the plastic zone along the shaft, we obtain an additional equilibrium equation:

$$
q(z)-q_{o}=0
$$

Thus, under elasto-plastic deformation of shaft-soil interface, the following governing equations are obtained:

$$
\frac{\mathrm{d}^{2} u}{\mathrm{~d} \xi^{2}}-\lambda^{2} u(\xi)=0 \quad \text { for } 0 \leq \xi \leq \xi_{0}
$$

and

$$
\frac{\mathrm{d}^{2} u}{\mathrm{~d} \xi^{2}}-\lambda^{2} u_{o}=0 \quad \text { for } \xi_{o} \leq \xi \leq 1
$$

The interface displacement at yield, $u_{o}=q_{o} / K$, and the location along the shaft of the transition from the elastic zone to the plastic zone is denoted by $\xi_{\mathrm{o}}$. To satisfy continuity of displacement and equilibrium at the transition point $\xi_{\mathrm{o}}$, the following boundary conditions must be satisfied:

$$
\left[u\left(\xi_{\mathrm{o}}\right)\right]^{E}=\left[u\left(\xi_{\mathrm{o}}\right)\right]^{P} \text { and }\left[\frac{\mathrm{d} u\left(\xi_{\mathrm{o}}\right)}{\mathrm{d} \xi}\right]^{E}=\left[\frac{\mathrm{d} u\left(\xi_{\mathrm{o}}\right)}{\mathrm{d} \xi}\right]^{P}
$$

where superscript $E$ refers to the elastic zone and superscript $P$ refers to the plastic zone along the shaft as described by Equations (12) and (13), respectively.

Considering that the shaft has an applied load, $P$, at the top and the tip force given by Equation (5), Equations (12) and (13) yield the following expressions for normalized shaft deformation in the interaction zone:

$$
U(\xi)=\frac{1}{\alpha} u(\xi)=\frac{\cosh \lambda \xi+\kappa \lambda \sinh \lambda \xi}{\lambda^{2}\left(\cosh \lambda \xi_{\mathrm{o}}+\kappa \lambda \sinh \lambda \xi_{\mathrm{o}}\right)} \quad \text { for } 0 \leq \xi \leq \xi_{\mathrm{o}}
$$

and

$$
U(\xi)=\frac{1}{\alpha} u(\xi)=\frac{1}{2}\left(\xi^{2}-\xi_{\mathrm{o}}^{2}\right)-\left(1-\frac{P}{P_{\mathrm{u}}}\right)\left(\xi-\xi_{\mathrm{o}}\right)+\frac{1}{\lambda^{2}} \quad \text { for } \xi_{\mathrm{o}} \leq \xi \leq 1
$$

The condition of continuity of displacements at the elastic to plastic transition point yields the following identity, which can be solved for a given load $P$ to obtain the location of transition point $\xi_{\mathrm{o}}$ :

$$
\left(\xi_{\mathrm{o}}-1\right)-\frac{\tanh \lambda \xi_{\mathrm{o}}}{\lambda}+\frac{P}{P_{\mathrm{u}}}-\frac{1}{\cosh \lambda \xi_{\mathrm{o}}}\left[\frac{\kappa}{\cosh \lambda \xi_{\mathrm{o}}+\kappa \lambda \sinh \lambda \xi_{\mathrm{o}}}\right]=0
$$


From Equation (17), it is seen that the yielding behavior of the shaft-soil interface not only depends upon the load ratio $P / P_{\mathrm{u}}$, it also depends upon the scaling factor $\lambda$ and the non-dimensional factor $\kappa$ that embody the effects of shaft length, shaft stiffness, shaft-soil interface stiffness, and tip soil stiffness. The scaled shaft displacement, $\bar{u}$, at the shaft head under an applied load, $P$, is given by:

$$
\bar{U}=\frac{1}{2}\left(1-\xi_{\mathrm{o}}^{2}\right)-\left(1-\frac{P}{P_{\mathrm{u}}}\right)\left(1-\xi_{\mathrm{o}}\right)+\frac{1}{\lambda^{2}}+\frac{P}{P_{\mathrm{u}}} \frac{L_{\mathrm{d}}}{L_{\mathrm{b}}} \quad \text { for } 0 \leq \xi_{\mathrm{o}} \leq 1
$$

Rewriting Equation (18), the shaft head displacement, $\bar{u}$, under an applied load, $P$, is given as:

$$
\bar{u}=\frac{1}{2} \frac{q_{\mathrm{o}} L_{\mathrm{b}}^{2}}{K_{\mathrm{m}}}\left(1-\xi_{\mathrm{o}}^{2}\right)-\frac{L_{\mathrm{b}}\left(q_{\mathrm{o}} L_{\mathrm{b}}-P\right)}{K_{\mathrm{m}}}\left(1-\xi_{\mathrm{o}}\right)+u_{\mathrm{o}}+\frac{P L_{\mathrm{d}}}{K_{\mathrm{m}}} \quad \text { for } 0 \leq \xi_{\mathrm{o}} \leq 1
$$

When the shaft-soil interface yields completely (i.e. $\xi_{\mathrm{o}}=0$ ), the tip carries the additional applied load and the normalized shaft deformation is given by:

$$
U(\xi)=\frac{1}{\alpha} u(\xi)=\frac{1}{2} \xi^{2}+\left(\frac{P}{P_{\mathrm{u}}}-1\right) \xi+\left(\frac{P}{P_{\mathrm{u}}}-1\right) \frac{1}{\lambda^{2} \kappa} \quad \text { for } 0 \leq \xi \leq 1
$$

When the tip force, $P_{\mathrm{t}}$, calculated from Equation (5), reaches the tip bearing capacity, the drilled shaft fails by plunging. Drilled shaft tip bearing capacity may be obtained from bearing capacity theories for deep foundations assuming a punching shear failure (see for example Coduto, 2001).

\section{Determination of Shaft-Soil Interface Properties}

The shaft-soil interface properties have a complex dependency upon the soil properties and construction techniques. These properties may be empirically obtained by analyzing the measured load-displacement curve obtained from a load test at given installations. The shaft-soil interface properties are related to the drilled shaft initial stiffness, $\mathrm{d} P / \mathrm{d} u$, and the ultimate pullout capacity or the load corresponding to yield under shaft compression denoted by $P_{\mathrm{u}}$. From Equation (10), the drilled shaft initial stiffness may be related to the scaling parameter, $\lambda$, interaction length, $L_{\mathrm{b}}$, and axial stiffness, $K_{\mathrm{m}}$, by the following expression:

$$
\frac{\mathrm{d} P}{\mathrm{~d} u}=\frac{\lambda K_{\mathrm{m}}}{L_{\mathrm{b}} \operatorname{coth} \lambda+L_{\mathrm{d}} \lambda}
$$

Thus, the scaling parameter, $\lambda$, and consequently, the shaft-soil interface shear modulus of sub-grade reaction, $K$, may be computed from measured loaddisplacement curves. The ultimate shear strength, $\tau_{\mathrm{u}}$, may be similarly obtained from measured load corresponding to yield, $P_{\mathrm{u}}$.

The shaft-soil interface properties used in the Monte Carlo simulation reported in this paper were obtained using load test data provided by Phoon et al. (1995). For 
each load test, the shaft diameter, shaft length, ultimate load, ultimate displacement, and displacement at $50 \%$ of the ultimate load were given. This data was used to back-calculate values of $\tau_{\mathrm{u}}$ and $K$ from each load test. Since a majority of the load test data was for drilled shafts installed in clay, the modulus of elasticity $=75 \mathrm{MPa}$, and Poisson's ratio $=0.4$ was assumed for the tip soil to calculate the value of $K_{\mathrm{t}}$ used in Equation (6). The mean values of $\tau_{\mathrm{u}}$ and $K$ from the entire data set were calculated to be $90 \mathrm{kPa}$ and $89 \mathrm{MPa}$, respectively. The coefficient of variation for each random variable was set at 0.30 , assuming typical variability of the shaft-soil interface for a given site, and the standard deviation of each soil property was based upon this value.

In Figure 5, we plot typical load-displacement curves based upon a deterministic closed-form shaft head displacement solution using the back-calculated mean values of $\tau_{\mathrm{u}}=90 \mathrm{kPa}$ and $K=89 \mathrm{MPa}$. We also plot the load displacement curve based upon an empirical hyperbolic equation proposed by Phoon et al. (1995) as a best fit to the measured load test data. Literature review suggests that the shaft side resistance becomes fully plastic along the length, $L_{\mathrm{b}}$, at a shaft head displacement of $10 \mathrm{~mm}$. From the closed-form solution given in Figure 5, it is apparent that the side resistance soil becomes fully plastic at a displacement of approximately $4 \mathrm{~mm}$. Because the closed form solution utilizes an ideal elasto-plastic shaft-soil interface model, the calculated load-displacement curve does not completely capture the nonlinear behavior. However, it is encouraging that the simple closed form solution presented here replicates the main features of the load-displacement curves. The closed form solution closely matches the initial stiffness of the hyperbolic curve as well as the post-yield hardening behavior. For illustration, we also plot the loaddisplacement curves that are obtained using mean $\tau_{\mathrm{u}}$ and $K \pm 1$-standard deviation.

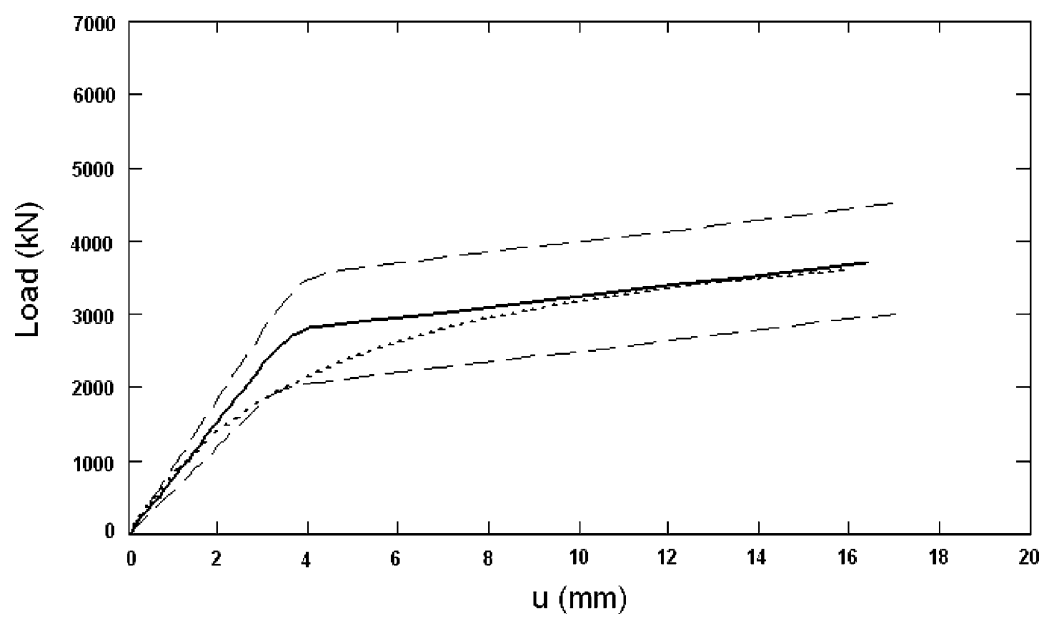

Figure 5. Load-displacement curve based upon closed-form displacement solution. Dashed lines are \pm 1 -standard deviation from deterministic solution. The dotted line is based upon an equation given by Phoon et al. (1995) for drilled shafts under compression. 


\section{Probabilistic Load-Displacement Relationships}

A computer program was written utilizing Mathcad software to solve for the drilled shaft head displacement. The Mathcad program generates a random value for $K$ and $\tau_{\mathrm{u}}$ within the defined probability distribution function and uses these values in Equations (10), (19), and (20) to solve for drilled shaft head displacement. As mentioned previously, 5000 trials were performed. The load-displacement curves from the first 20 trials are plotted in Figure 6 along with the deterministic loaddisplacement curve obtained from mean values of the properties. Classic load-displacement curves are obtained characterized by an initial steep curve, a yield point at which the shaft-soil interface completely yields, followed by a hardening curve during which the additional load is supported by the shaft tip.

\subsection{ALLOWABLE DISPLACEMENT EXCEEDANCE PROBABILITIES}

Based upon the probabilistic load-displacement simulations, the probability distribution of shaft head displacement at 2, 3 and $4 \mathrm{MN}$ loads were obtained as shown in Figure 7a. The corresponding cumulative probability distribution is plotted in Figure $7 \mathrm{~b}$. We find that the resulting distribution of displacements do not fit the lognormal distribution. Moreover, the distributions vary significantly with increase in load. Since the displacements are a complex function of shaft-soil interface properties, such a result is expected. At low loads, the likelihood of the drilled shaftsoil interface completely yielding is small; therefore, the displacements are distributed in a narrow range. At higher loads, the distribution becomes broader as more and more load-displacement curves reach yield. It can be observed that the

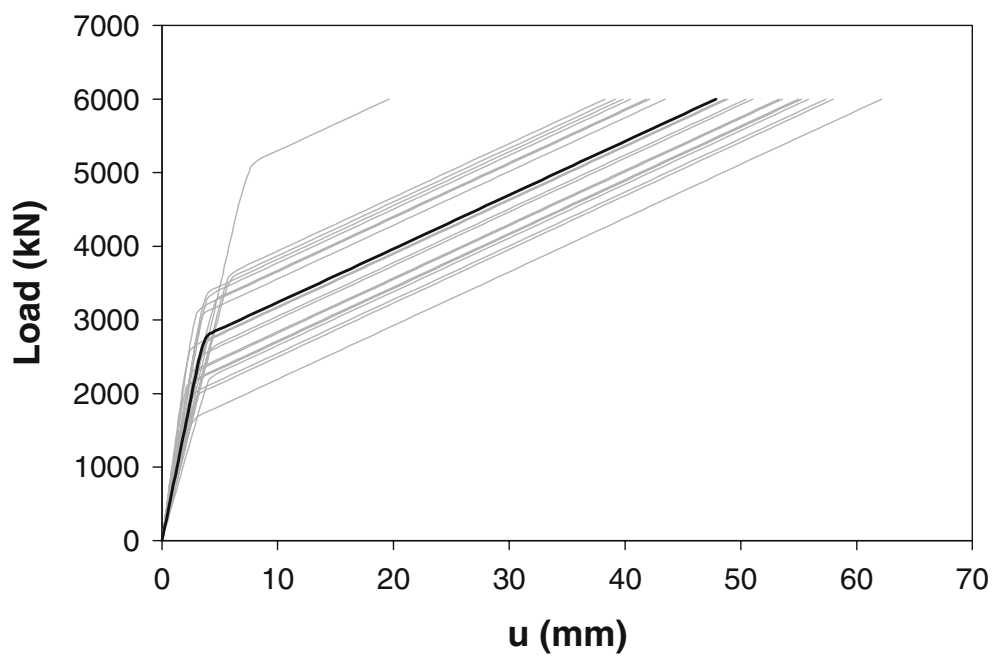

Figure 6. Load-displacement curve for 20 realizations based upon lognormal distribution (dark line indicates deterministic results). 

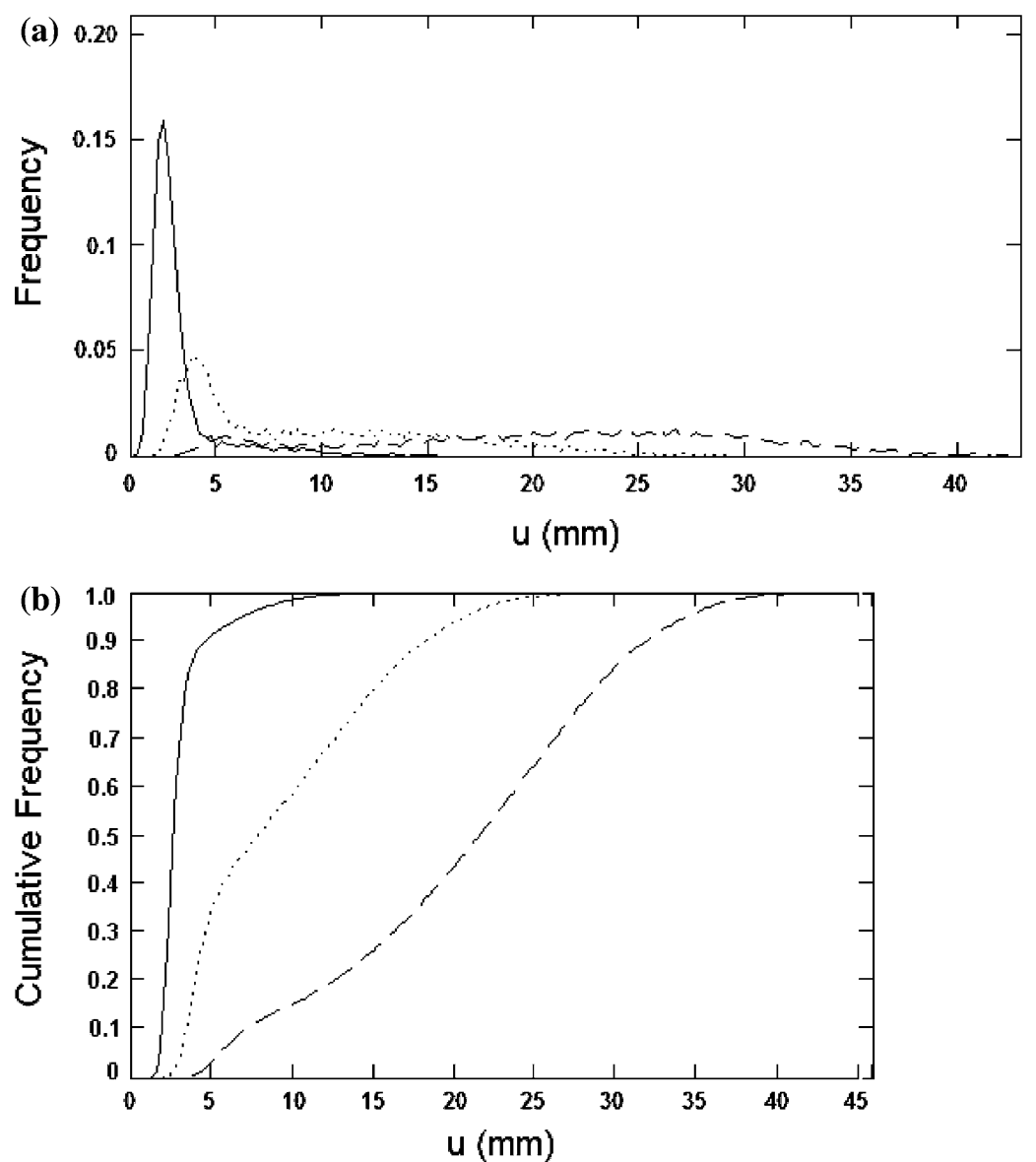

Figure 7. (a) Probability distribution histograms for shaft head displacement when drilled shaft is subjected to loads of 2, 3, and $4 \mathrm{MN}$, respectively. (b) Cumulative distribution histograms for shaft head displacement when drilled shaft is subjected to loads of 2, 3, and $4 \mathrm{MN}$, respectively.

distribution for the shaft head displacement at a load of $2 \mathrm{MN}$ is rather small, encompassing a range of less than $10 \mathrm{~mm}$; conversely, the distribution for the shaft head displacement at a load of $4 \mathrm{MN}$ is rather large, encompassing a shaft head displacement range of nearly $40 \mathrm{~mm}$.

For the purposes of demonstrating the concept of exceedance probability, distribution histograms were developed based upon an allowable drilled shaft displacement of $10 \mathrm{~mm}$. For this study, an allowable displacement of $10 \mathrm{~mm}$ was used for convenience. Although there does appear to be some literature on the subject of allowable vertical displacements for foundations, the values seem to be greatly varied. NCHRP Report 343 provides a table of allowable displacements for bridges expressed in terms of settlement magnitude (Barker et al., 1991). The range of the displacement magnitude is from $51 \mathrm{~mm}$, termed as "not harmful," to $102 \mathrm{~mm}$, termed as "harmful but tolerable." A settlement criterion in terms of angular 
distortion is also provided in the NCHRP Report and is expressed in terms of tolerable movements for single-span and multiple span bridges.

In Figure 8, we have plotted the probability that the allowable displacement will be exceeded at a given load. From the 5000 simulations generated at each load, the number of simulations exceeding the allowable displacement is determined. The probability is computed as the number of simulations exceeding the allowable displacement divided by the total number of trials. At small loads, the numbers of simulations that exceed the allowable displacement are small, thus the exceedance probability is small. As the load-level increases, the numbers of simulations that exceed the allowable displacement will increase. Finally, at a certain load, it is likely that the allowable displacement is always exceeded. From Figure 8, we see that at a load of $5800 \mathrm{kN}$, the probability of exceedance of the $10 \mathrm{~mm}$ allowable displacement is $100 \%$. Alternatively, the load corresponding to $50 \%$ probability of exceedance of the $10 \mathrm{~mm}$ allowable displacement is approximately $3000 \mathrm{kN}$. Thus, these exceedance probability curves may be applied to evaluate the likelihood that the drilled shaft will exceed an allowable displacement at the design load.

\subsection{LOAD CAPACITY PROBABILITY DISTRIBUTION}

The load-displacement curves generated from the simulations may also be analyzed to determine the drilled shaft load capacity at a given allowable displacement. In Figure 9, we have plotted the probability distribution function for the load capacity at an allowable head displacement of $10 \mathrm{~mm}$. The corresponding cumulative distribution function is plotted in Figure 10.

The probability distribution function from Figure 9 may be used to develop resistance factors at a given allowable displacement provided that the probability distribution function of the loads acting on the drilled shaft are known based upon

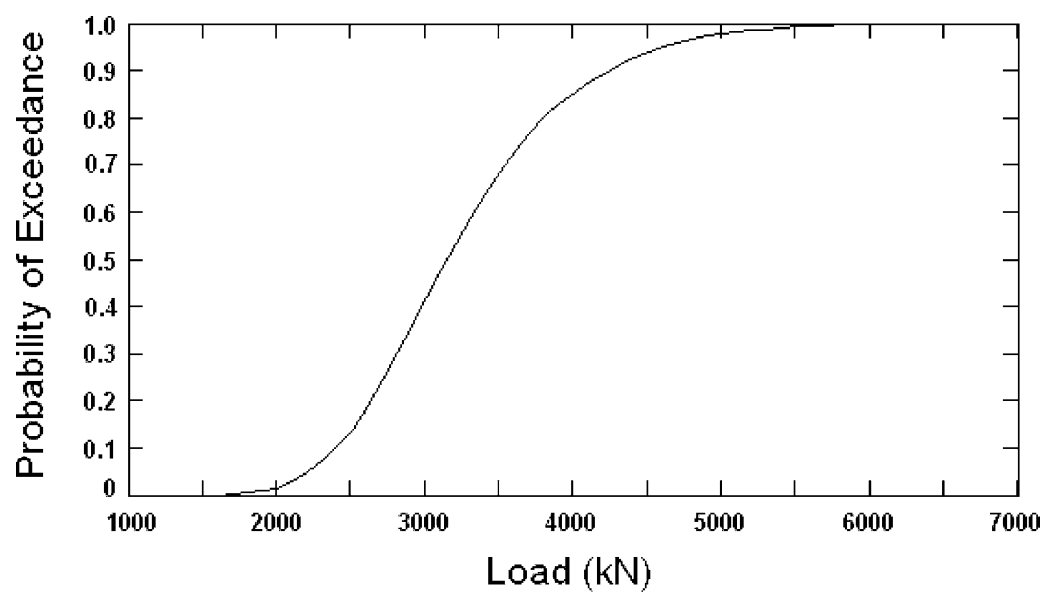

Figure 8. Exceedance probability curve for an allowable shaft head displacement of $10 \mathrm{~mm}$. 


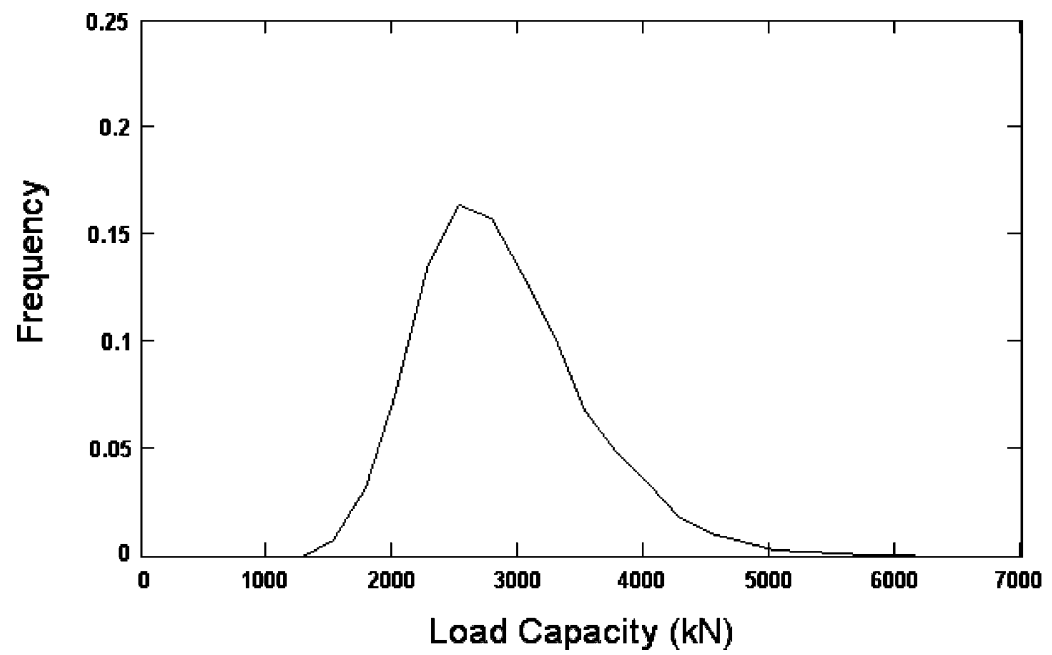

Figure 9. Probability distribution histogram for shaft service limit state load capacity given an allowable shaft head displacement of $10 \mathrm{~mm}$.

LRFD service load criteria. To that end, the probability of exceeding the allowable displacement can also be calculated based upon the load and load capacity distribution functions. Figure 10 provides the probability that the load capacity will be equal to or less than the required load capacity for a given allowable displacement. For example, the probability that the load capacity of the drilled shaft is less than or equal to $3000 \mathrm{kN}$ is approximately 0.50 for an allowable displacement of $10 \mathrm{~mm}$. If $10 \mathrm{~mm}$ were the absolute allowable displacement, this probability is most likely too

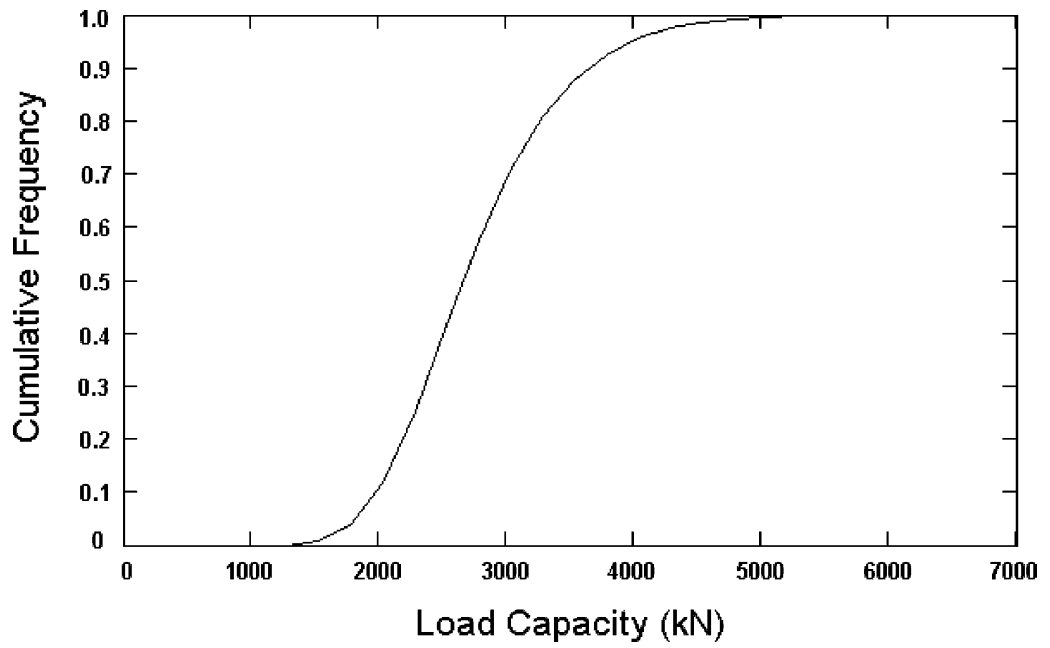

Figure 10. Cumulative distribution histogram for shaft service limit state load capacity given an allowable shaft head displacement of $10 \mathrm{~mm}$. 
high, and the designer would then need to adjust the design to produce a much lower probability. For a designer to meet the criteria of a high reliability, a load of $1800 \mathrm{kN}$ or less is most likely appropriate

\subsection{CASE HISTORY}

For practical design, it may be desirable to represent the probability and cumulative distribution histograms given in Figures 9 and 10 by a factor of safety histogram. Assuming the load on the drilled shaft to be deterministic, the factor of safety of the drilled shaft at the service limit state may be expressed as:

$$
\mathrm{FS}=\frac{R}{Q}
$$

where $Q=$ load on the drilled shaft and $R=$ drilled shaft load capacity. Since the drilled shaft load capacity is a probability distribution function given in Figure 9, Equation (22) will result in a probability distribution function for the factor of safety. When the factor of safety is calculated to be less than unity, failure of the drilled shaft at the service limit state will occur. Therefore, assuming that the drilled shaft load capacity histogram (and consequently, the factor of safety histogram) follows a lognormal distribution, the probability of drilled shaft failure at the service limit state can be calculated as:

$$
P_{\mathrm{f}}=P(\mathrm{FS} \leq 1)=\Phi\left(\frac{\ln (1)-\mu_{\operatorname{lnFS}}}{\sigma_{\ln \mathrm{FS}}}\right)
$$

where $\mu_{\ln }$ FS is the log mean of the factor of safety, $\sigma_{\ln \text { FS }}$ is the log standard deviation of the factor of safety, and $\Phi()$ is the cumulative standard normal distribution function. If we assume, for example, that the load on the drilled shaft is equal to $2000 \mathrm{kN}$, the probability distribution and cumulative distribution histograms given in Figures 11 and 12 are obtained for the factor of safety using Equation (22).

Using Equation (23), the probability of drilled shaft failure at the service limit state (10 mm allowable displacement) was calculated to be $2.2 \%$, which corresponds approximately to a reliability index, $\beta$, of 2.0. The reliability index is an alternate method of measuring the probability of failure on a more convenient scale as the probability of failure can be difficult to assess when its value is small (Kulhawy and Phoon, 1996). Standard statistics textbooks provide the relationship between probability of failure and the reliability index. At the service limit state, it has been suggested that the reliability index be equal to 2.6 (Phoon et al., 1995), which approximately corresponds to a probability of failure of $0.5 \%$. Therefore, in the design scenario presented here, the drilled shaft must be revised until the reliability index is increased to 2.6 (i.e. the probability of failure is decreased). Alternatively, the load capacity at the service limit state should be reduced to $1800 \mathrm{kN}$. For simplicity, the probability of failure can also be determined directly from the cumulative distribution histogram in Figure 12. 


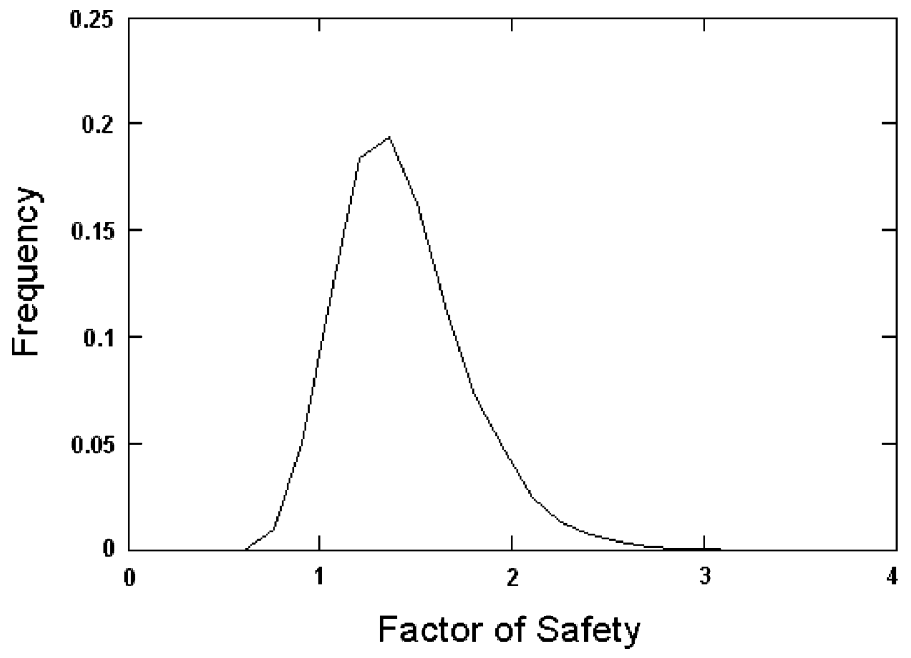

Figure 11. Probability distribution histogram for factor of safety against service limit state failure based upon a drilled shaft load of $2000 \mathrm{kN}$.

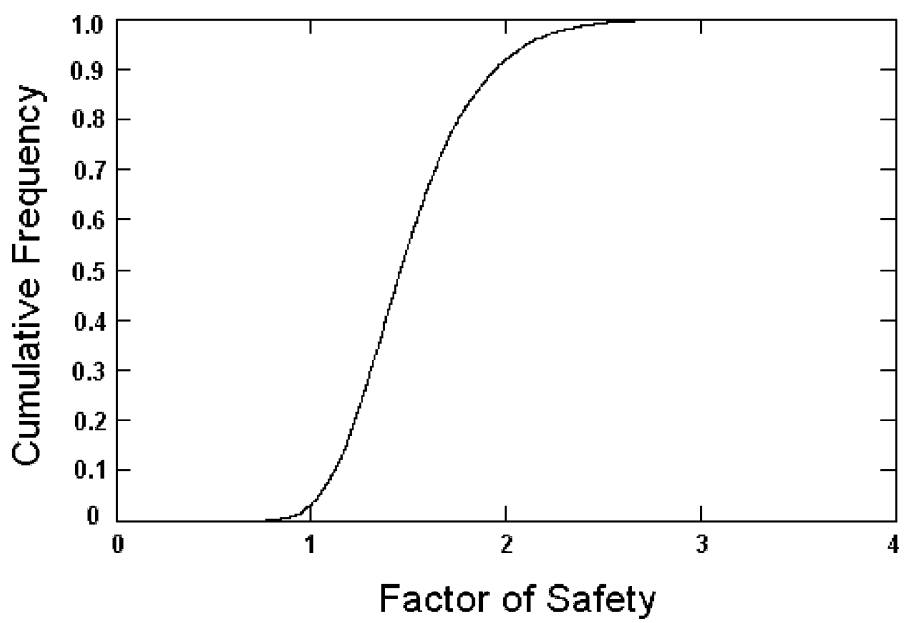

Figure 12. Cumulative distribution histogram for factor of safety against service limit state failure based upon a compression load of $2000 \mathrm{kN}$.

The development of the factor of safety histograms, and consequently the calculation of the probability of service limit state failure, was based upon a deterministic value of load applied to the drilled shaft rather than a load defined by a random variable. This approach is somewhat similar to the serviceability design methods presently utilized by practicing engineers; current methods are often based upon calculating a factor of safety for serviceability failure by dividing the drilled shaft service load capacity by a single deterministic load. However, the drawback with the current method is the fact that the drilled shaft service load capacity is not 
determined based upon probabilistic theory, but rather using nominal values for soil properties. Therefore, using probabilistic theory, and defining soil properties in terms of random variables, provides a robust and powerful method for determining service limit state failure for drilled shafts.

\section{Summary and Conclusions}

A mathematical model is presented for drilled shaft load-displacement behavior under compression. The shaft-soil interaction is explicitly considered in the model development. To ensure model simplicity and accessibility to designers, the shaft-soil interface is assumed to be homogeneous with depth, elastic-perfectly plastic characterized by the shear modulus of the shaft-soil interface sub-grade reaction $K$, and the ultimate shaft-soil interface shear strength $\tau_{\mathrm{u}}$. Closed form expressions for drilled shaft load-displacement are obtained for compressive and pullout loading under both elastic and elasto-plastic deformation of shaft-soil interface. Since the derived closed form solutions are complex, the Monte Carlo simulation method was used to perform the probabilistic load-displacement analysis. For these simulations, the shaft-soil interface properties were assumed to be random variables and were characterized statistically by the lognormal probability distribution function. Probability curves were generated in order to quantify the probability of drilled shaft failure at the service limit state based upon an allowable head displacement.

Two methods for determining the probability of drilled shaft failure at the service limit state have been proposed. In the first method, the factored load acting on the drilled shaft is assumed to be known. Based upon this load, a probability distribution histogram may be created for the range of possible displacements. We find that as the value of the desired load increases, the variability in the displacement increases resulting in a histogram with a narrow peak and a long tail to the right. This approach can be appropriate for describing a range of possible allowable displacements and their corresponding probabilities. However, this method forces the designer to choose the level of reliability at the service limit state. Although this can be an ambiguous task, service limit state levels of reliability have been defined in the literature, including Phoon et al. (1995), and are based upon achieving a certain reliability index. The reliability index at the service limit state is usually smaller than at the ultimate limit state due to the consequences of exceeding an allowable displacement being less than exceeding an ultimate capacity.

In the second method, the probability of service limit state failure is determined based upon an allowable displacement. The designer must decide the value of this allowable displacement based upon tolerable movement limits for the structure. The load capacity histogram for a given allowable displacement is obtained from the Monte Carlo simulations. The load capacity histogram may be used to develop resistance factors at a given allowable displacement provided that the probability distribution function of the loads acting on the drilled shaft are known based upon LRFD ultimate strength criteria. In addition, factor of safety histograms may be 
created and the probability of service limit state failure calculated using standard probability statistics.

Although both of these methods are somewhat cumbersome for the designer to use and require the development of probability distribution histograms based upon some advanced probabilistic analysis technique such as Monte Carlo simulation, this process is a necessary step for developing resistance factors at the service limit state. In addition, both procedures demonstrate that a reliability based design process may indeed be developed for the service limit state. Ultimately, the development of probability distribution curves for the drilled shaft load capacity based upon an allowable displacement is desired.

\section{References}

AASHTO (2004) LRFD Bridge Design Specifications, 3rd edition, American Association of State Highway and Transportation Officials, Washington, DC.

Baecher, G.B. and Christian, J.T. (2003) Reliability and Statistics in Geotechnical Engineering, Wiley, West Sussex, UK.

Barker, R.M., Duncan, J.M., Rojiani, K.B., Ooi, P.S.K., Tan, C.K. and Kim, S.G. (1991) NCHRP Report 343: Manuals for the Design of Bridge Foundations, Transportation Research Board National Research Council, Washington, DC.

Chalermyanont, T. and Benson, C.H. (2004) Reliability-based design for internal stability of mechanically stabilized earth walls, Journal of Geotechnical and Geoenvironmental Engineering, 130(2), 163-173 ASCE.

Christian, J.T. (2004) Geotechnical engineering reliability: how well do we know what we are doing? Journal of Geotechnical and Geoenvironmental Engineering, 130(10), 985-1003 ASCE.

Coduto, D.P. (2001) Foundation Design: Principles and Practices, Prentice-Hall, New Jersey.

FHWA (1999) Drilled Shafts: Construction Procedures and Design Methods, Federal Highway Administration US Department of Transportation, Mclean, VA Report No. FHWAIF-99-025.

Griffiths, D.V. and Fenton, G.A. (2004) Probabilistic slope stability analysis by finite elements, Journal of Geotechnical and Geoenvironmental Engineering, 130(5), 507-518 ASCE.

Harr, M.E. (1996) Reliability-Based Design in Civil Engineering, Dover Publications Inc., Mineola, New York.

Johnson, K.L. (1985) Contact Mechanics, Cambridge University Press, London, UK.

Kraft, L.M., Ray, R.M. and Kagawa, T. (1981) Theoretical t-z curves, Journal of Geotechnical Engineering, 107(11), 1543-1561 ASCE.

Kulhawy, F.H. and Phoon, K.K. (1996) "Engineering judgment in the evolution from deterministic to reliability-based foundation design", Uncertainty' 96, Geotechnical Special Publication No. 58, ASCE, New York, 1, 29-48.

Mathcad version 11 (2002). Mathsoft Engineering \& Education, Inc., Cambridge, MA.

Misra, A. and Chen, C.-H. (2004) Analytical solutions for micropile design under tension and compression, Journal of Geotechnical and Geological Engineering, 22(2), 199-225.

Paikowsky, S.G., Birgisson, B., McVay, M., Nguyen, T., Kuo, C., Baecher, G., Ayyub, B., Stenersen, K., O'Malley, K., Chernauskas, L. and O'Neill, M. (2004) NCHRP Report 507: Load and Resistance Factor Design (LRFD) for Deep Foundations, Transportation Research Board, National Research Council, Washington, DC. 
Phoon, K.-K., Kulhawy, F.H. and Grigoriu, M.D. (1995) "Reliability-Based Design of Foundations for Transmission Line Structures," Report TR-105000, Electric Power Research Institute, Palo Alto, CA, July 1995, 380 p.

Phoon, K.K. and Kulhawy, F.H. (1999) Characterization of geotechnical variability, Canadian Geotechnical Journal, 36(4), 612-624.

Reese, L.C. and O'Neill, M.W. (1987) Drilled Shafts: Construction Procedures and Design Methods, in Report No. FHWA-HI-88-042, Federal Highway Administration, U.S. Department of Transportation, McLean, Virginia.

Scott, R.F. (1981) Foundation Analysis, Prentice-Hall, New Jersey. 